\title{
Venous thromboembolism prophylactic methods in acute stroke patients - current state of knowledge
}

\author{
Metody profilaktyki żylnej choroby zakrzepowo-zatorowej u chorych w ostrej fazie \\ udaru mózgu - aktualny stan wiedzy
}

Jan Paweł Bembenek', Anna Członkowska ${ }^{1,2}$

12nd Department of Neurology, Institute of Psychiatry and Neurology, Warsaw, Poland

2Department of Experimental and Clinical Pharmacology, Medical University of Warsaw, Warsaw, Poland

Neurologia i Neurochirurgia Polska 2013; 47, 6: 564-571

DOl: 10.5114/ninp.2013.39074

\begin{abstract}
Deep venous thrombosis (DVT) and its sequel, pulmonary embolism (PE), are serious complications of stroke. There are pharmacological and physical methods to prevent these complications. The authors review the literature and present the current state of knowledge regarding the effectiveness of each of the DVT and PE prevention methods in stroke patients and cite current Polish, European and American recommendations regarding this issue. Heparins are the method of choice for the prevention of venous thromboembolism in both ischaemic and haemorrhagic stroke patients.
\end{abstract}

Key words: venous thromboembolism, deep venous thrombosis, stroke, prophylaxis.

\section{Introduction}

\section{The importance of post-stroke deep venous thrombosis}

Deep venous thrombosis (DVT) and its sequel, pulmonary embolism (PE), are important causes of illness

\section{Streszczenie}

Zakrzepica żył głębokich kończyn i jej konsekwencja - zatorowość płucna, są poważnymi powikłaniami udaru mózgu. Istnieją farmakologiczne i fizyczne metody zapobiegania tym powikłaniom. Autorzy dokonują przeglądu piśmiennictwa i prezentują aktualny stan wiedzy na temat skuteczności każdej z metod stosowanych w profilaktyce zakrzepicy żył głębokich kończyn i zatorowości płucnej u chorych po udarze mózgu, a także cytują aktualne zalecenia polskie, europejskie i amerykańskie. Stosowanie heparyn jest metodą z wyboru w zapobieganiu powikłaniom zakrzepowo-zatorowym u unieruchomionych chorych z udarem mózgu, zarówno niedokrwiennym, jak i krwotocznym.

Słowa kluczowe: zakrzepica żył głębokich kończyn dolnych, zatorowość płucna, udar mózgu, profilaktyka.

and death after stroke [1]. Patients who are immobile, with significant weakness of the limbs and with a prior history of DVT are at greatest risk of DVT development [2]. In studies using magnetic resonance imaging to detect thrombus, DVT occurred in $40.2 \%$ of stroke patients within the first three weeks, of which $17 \%$ was aboveknee DVT [3]. However, studies in which Doppler

Correspondence address: Jan Bembenek, 2nd Department of Neurology, Institute of Psychiatry and Neurology, 9 Sobieskiego St, 02-957 Warsaw, phone: + 4822 4582872, fax: + 4822 8424023, e-mail: jbembenek@02.pl

Received: 12.01.2013; accepted: 13.03.2013 
ultrasound was used as a screening technique suggest a lower frequency of above-knee DVT of perhaps 'only' $10-11 \%$, although the types of patients included and the duration and timing of follow-up influence the estimates $[4,5]$. Some studies suggest even that the frequency of both distal and proximal DVT reaches slightly more than $11 \%$ (above-knee DVT - 1\%) [6]. Discrepancies in the results are due to methodological differences of those studies. Moreover, patients with acute stroke and increased C-reactive protein (CRP) level seem to be at substantial risk of new clot formation [7]. Most DVTs are clinically silent so symptomatic ones seem to be the tip of the iceberg of the problem [7]. Clinically not recognized DVTs still may cause important complications. Above-knee DVT is associated with great risk of $\mathrm{PE}$ and is responsible for $90 \%$ of total PE. Clinically evident $\mathrm{PE}$ in the early phase of stroke has been variably estimated, depending on the type of study: to affect one to $16 \%$ of patients in prospective trials $[8,9]$, and $3-30 \%$ in observational studies [10].

\section{Deep venous thrombosis prophylactic methods}

There are pharmacological (unfractionated heparin - UFH, low-molecular-weight heparins - LMWH, oral anticoagulants, new oral anticoagulants, dextrans) and physical methods (graduated compression stockings [GCS], intermittent pneumatic compression [IPC] devices) which aim to reduce the risk of venous thromboembolism (VTE). Proper hydration and early mobilization are also regarded as prophylactic methods.

\section{Pharmacological methods to prevent post-stroke venous thromboembolism}

\section{Heparins}

There is a large amount of data supporting the use of anticoagulants (heparins in perioperative period followed by new and old oral anticoagulants) in patients undergoing surgical procedures, to prevent thromboembolic complications; hence they are strongly recommended in this group of patients [11].

The situation regarding the use of anticoagulants in the prevention of VTE in stroke patients is more complicated, as there is lack of studies evaluating their efficacy and safety in this group of patients, and haemorrhagic complications are relatively frequent. The Coch- rane review identified four trials which compared LMWH (enoxaparin or certoparin), and one trial compared an unspecified LMWH with standard unfractionated heparin in stroke patients [12]. Allocation to LMWH or heparinoid was associated with a significant reduction in the odds of deep vein thrombosis compared with standard unfractionated heparin (odds ratio [OR] $0.55,95 \%$ confidence interval $[\mathrm{CI}] 0.44$ to 0.70 ). However, the number of major events (pulmonary embolism, death, intracranial or extracranial haemorrhage) was too small to provide a reliable estimate of the benefits and risks of LMWH or heparinoids compared with standard UFH for these, arguably more important, outcomes.

Unfractionated heparins were extensively studied in the 1990s. However, evidence from the International Stroke Trial [13] shows that even low dose heparin (5,000 units twice daily) is associated with a significant excess of symptomatic intracranial and extracranial bleeds which offset any other advantages heparin may have in recurrent ischaemic stroke and fatal PE. What is more, compared with 5000 IU b.i.d. heparin, 12,500 IU b.i.d. heparin was associated with significantly more transfused or fatal extracranial bleeds, more haemorrhagic strokes, and more deaths or non-fatal strokes within 14 days $(12.6 \%$ vs. $10.8 \%)$. However, it should be stressed that in this study PE prevention was additionally analyzed as a secondary endpoint.

There have been no studies comparing UFH with LMWH in VTE prevention as a primary endpoint in stroke patients. The largest trial to date was published in 2007 (PREVAIL trial), and compared the effectiveness and safety of UFH with LMWH [14]. It demonstrated that LMWH (enoxaparin $40 \mathrm{mg}$ daily) was probably more effective than standard heparin (5000 IU twice daily) in preventing mainly asymptomatic DVTs but it was not powered to identify clinically significant differences in risk. More importantly, it does not provide any evidence that routine heparin or LMWH use is associated with net benefit, because there was no 'avoid any heparin' control group.

The newest study (EXCLAIM study) evaluated the use of enoxaparin $40 \mathrm{mg}$ for $10 \pm 4$ days, in acutely ill patients (including patients with acute ischaemic stroke) [15]. Patients were randomized to double-blind enoxaparin $40 \mathrm{mg}$ daily or placebo for a further $28 \pm 4$ days in VTE prophylaxis. In total, 389 of 5963 (6.5\%) randomized patients had ischaemic stroke. Some of them $(n=198)$ received extended-duration prophylaxis and 191 received placebo. Extended-duration enoxaparin significantly reduced VTE incidence versus placebo 
(2.4\% vs. $8.0 \%$; absolute risk difference, $-5.6 \%$; $95 \% \mathrm{CI}$ : $-10.5 \%$ to $-0.7 \%)$, but it was associated with an increased incidence of major bleeding $(1.5 \%$ vs. $0 \%$ in enoxaparin and placebo groups; absolute risk difference, $+1.5 \%$; $95 \%$ CI: $-0.2 \%$ to $3.2 \%$ ).

Authors of the literature review suggest that, despite the lack of large clinical trials in acute stroke patients, preferential use of enoxaparin over UFH for the prevention of VTE after acute ischaemic stroke may lead to reduced VTE rates and concomitant cost savings in clinical practice [16].

Both European and American guidelines recommend the use of heparins (UFH and LMWH) to prevent VTE in stroke patients, but suggest their use mostly in those considered to be at high risk of VTE and low risk of bleeding - interpretation of this recommendation may be problematic and controversial $[17,18]$. Most recent Polish guidelines on VTE prophylaxis suggest the use of heparins as a method of choice in both ischaemic and haemorrhagic stroke patients [19]. LMWH should be preferred over UHF [19].

\section{Oral anticoagulants}

Anticoagulants and new oral anticoagulants have not been evaluated for VTE prophylaxis in acute stroke patients. Available studies included patients in the rehabilitation phase following cerebral infarction and were flawed by a significant number of losses to follow-up evaluation [20]. Anticoagulants are contraindicated in the acute phase of both ischaemic and haemorrhagic stroke to prevent VTE and as a secondary stroke prevention [21]. This may explain the lack of studies evaluating anticoagulants in VTE prevention in acute stroke patients. Nevertheless, patients with confirmed DVT or $\mathrm{PE}$ should receive a therapeutic dose of LMWH or UFH followed by oral anticoagulants, which is consistent with the treatment of patients with other acute medical illnesses $[19,21]$.

\section{Aspirin}

In 1977, aspirin (at a dose of $600 \mathrm{mg}$ twice daily) was shown to reduce the risk of VTE, when it was given to patients after they had undergone hip arthroplasty [22]. Thirty-five years later, guidelines still include aspirin as one of the options for preventing VTE after orthopaedic surgery [23]. Other trials have demonstrated that aspirin is possibly effective in preventing DVT and PE after other surgical procedures $[24,25]$. However, to date there are no data to support the use of aspirin to prevent DVT and/or PE in acute stroke patients. The results of the International Stroke Trial (IST) [13] and the Chinese Acute Stroke Trial (CAST) [26] suggest that aspirin should be started in all patients with excluded haemorrhagic and proven ischaemic stroke as soon as possible since it is associated with a reduced risk of death and recurrence of stroke within the first month. However, in those studies PE was a secondary endpoint which should be stressed, whilst the primary endpoint was any further stroke or death. In a meta-analysis of both of those studies (IST and CAST) the effect of aspirin in $\mathrm{PE}$ prevention was unclear as groups with $\mathrm{PE}$ were too small (30 in the aspirin group vs. 41 in controls) to draw any firm conclusions [27]. In the IST, although VTE was not a primary endpoint, aspirin was associated with risk reduction of $\mathrm{PE}$ in the first two weeks from $0.8 \%$ to $0.6 \%(2 p=0.08$, odds reduction $26 \%$ (95\% CI: $48 \%$ reduction to $4 \%$ increase) [13]. Nevertheless, aspirin should not be considered as a VTE prevention method as there are not enough data to support its use in DVT prevention [28]. A Cochrane review identified two small trials including 133 patients (fewer than $0.3 \%$ of the participants included in the overall review) and showed that antiplatelet therapy did not reduce the risk of VTE (OR: 0.78; 95\% CI: 0.36-1.67) [29]. Therefore, all patients with stroke, except those with haemorrhagic stroke or with other contraindications to aspirin, should be treated with aspirin but this should be regarded only as the secondary stroke prevention and not VTE prevention of immobile, post-stroke patients $[17,18]$.

For many years, aspirin was not recommended in stroke patients as a VTE prophylactic method due to the lack of data to support its effectiveness in VTE prophylaxis [30]. In the newest version of the American College of Chest Physicians (ACCP) recommendations accepted by Polish experts in 2012, aspirin is one of the VTE prophylaxis options, which seems controversial [19].

\section{Haemodilution and dextrans}

Haemodilution has been extensively studied as a potential prevention method for VTE complications in acute ischaemic stroke patients. A meta-analysis of the available randomized controlled trials (RCTs) suggests that it confers no benefit overall [31]. However, this analysis demonstrated that haemodilution was associated with a strong trend towards fewer DVTs. On the other hand, it is widely assumed that dehydration predisposes to VTE and this fits with one small observa- 
tion study evaluating a greater risk of dehydrated poststroke patients for VTE [32].

The use of dextrans in VTE prevention is not recommended in stroke patients as there are no data to support its effectiveness $[17,18]$.

Nevertheless, in many stroke units hydration is an important part of VTE prevention, despite the fact that it is not recommended by the newest Polish and American neurological society guidelines; hence this should not be a routine clinical practice $[18,21]$.

\section{Physical methods of venous thromboembolism prevention}

\section{Early mobilization}

Early mobilization is a standard procedure in surgical patients, to prevent thromboembolic complications [11].

It is also a part of DVT prophylaxis in post-stroke patients in many centres, although there is an ongoing debate about the definition and effectiveness of this method [33]. Nevertheless, this method is recommended by European Stroke Organization guidelines [17], as well as by the newest Polish guidelines of stroke treatment and prevention published in 2012 [21]. The latest American guidelines do not mention the use of this method [18]. There have been no trials evaluating the effectiveness of this method in VTE prevention in stroke patients. Moreover, the ongoing AVERT trial (A Very Early Rehabilitation Trial for Stroke) will also not answer whether this method is effective in VTE prevention as the aim of this study is to test its effect on functional outcomes but not VTE [34].

Immobile patients are at great risk of DVT [2]. It is therefore not surprising that early mobilisation and exercises involving foot extension improve venous flow and are a promising prophylactic measure. However, there is still no reliable evidence to support this thesis. Ongoing trials evaluating the effectiveness of early mobilisation hope to show some effectiveness [34].

\section{Graduated compression stockings}

Graduated compression stockings are commonly used in several surgical wards, as their effectiveness has been proved in patients after surgical procedures. At least three systematic reviews of randomised control studies (RCTs) evaluating GCS have concluded that graduated compression stockings are effective in peri- operative patients [35-37]. In 1994, a systematic review of GCS was published ( 11 trials, $n=1752$ ). In this review, the use of GCS in post-surgical patients was associated with $68 \%$ (95\% CI: $53-73 \%$ ) risk reduction of DVT. A more recent systematic review showed a $62 \%$ (95\% CI: $52-70 \%$ ) risk reduction of DVT in $2582 \mathrm{pa}-$ tients randomised in 18 trials [37]. The latter review demonstrated a 53\% (95\% CI: 3-83\%) reduction in PE amongst 1466 patients entered into 12 trials. Only two of the trials included randomised high-risk medical (rather than surgical) patients $[38,39]$. Too few DVTs occurred to provide any reliable estimate of their effectiveness in this context.

The first RCT to evaluate GCS in stroke patients was published in 2000 [39]. In this trial, 98 patients with an acute stroke were randomly allocated to one of three treatment groups: routine care, routine care plus Kendall TED stockings, or routine care plus Brevett TX stockings. At randomisation 9/97 (9\%) already had detectable popliteal thrombus with the use of Doppler ultrasound (USG) and five additional patients had detectable DVT by day 5 to 9 . Thus 14/97 (14\%) of patients had DVTs within 10 days of stroke onset. Of the five DVTs which occurred after randomisation, four occurred in the non-stocking group. Fifteen of $65 \mathrm{pa}-$ tients allocated to full length stockings and 10 of 32 allocated to the non-stocking group either died or had DVTs detected in Doppler ultrasound (OR 0.66; 95\% CI: 0.26-1.70). This small single centre trial was underpowered to demonstrate that differences between treatment groups were statistically significant.

In a large clinical trial published in 2009 [5] which was designed to evaluate the effectiveness of thigh-length GCS $(n=1256)$ versus routine care $(n=1262)$, proximal DVT on USG examination at 7-10 days after stroke was found in $10.0 \%$ and $10.5 \%$ of patients, respectively. The primary outcome was the occurrence of symptomatic or asymptomatic DVT in the popliteal or femoral veins. The primary outcome occurred in $126(10.0 \%)$ patients allocated to thigh-length GCS and in $133(10.5 \%)$ allocated to avoid GCS, which resulted in a non-significant absolute reduction in risk of $0.5 \%$ (95\% CI: $-1.9 \%$ to $2.9 \%)$. In the stocking-wearing group skin breaks, ulcers, blisters, and skin necrosis were significantly more common than in those allocated to avoid the use of GCS (64 [5\%] vs. 16 [1\%]; OR 4.18, 95\% CI: 2.40-7.27).

In the Clots 2 trial (Clots in Legs Or sTockings after Stroke) the authors compared the effectiveness of thighlength stockings with that of below-knee stockings for preventing proximal DVT in immobile, hospitalized 
patients with stroke. 1552 patients received thigh-length stockings and 1562 patients received below-knee stockings to wear while they were in the hospital. USG of the lower extremities was performed 7-10 days after stroke. The primary outcome was symptomatic or asymptomatic DVT in the popliteal or femoral veins, detected on either scan. The primary outcome occurred in $6.3 \%$ of patients who received thigh-length stockings and in $8.8 \%$ who received below-knee stockings (absolute difference, 2.5 percentage points [95\% CI: 0.7 to 4.4 percentage points]; $P=0.008)$, an odds reduction of $31 \%(95 \% \mathrm{CI}$ : $9 \%$ to $47 \%$ ) [40].

Generally, there is no great risk associated with wearing GCS. However, in patients with severe peripheral vascular disease and/or peripheral neuropathy they are contraindicated because their use can cause skin necrosis and occasionally this has necessitated even amputation $[41,42]$. Patients with stroke are more likely than surgical patients to suffer diabetes and peripheral vascular disease. Perhaps more significant than this small risk is the much more common experience of patients and nursing staff that GCS, especially the full length, are uncomfortable and may be difficult to apply in pa tients with limb weakness. In addition, many stroke patients are incontinent of urine and/or faeces, which can lead to soiling of the stockings and this can cause more problems with the underlying skin and greater discomfort. This was confirmed in the CLOTS 1 trial [5].

Both European and American guidelines recommend that GCS should not be routinely used in stroke patients [17-19,21].

\section{Intermittent pneumatic compression}

Intermittent pneumatic compression (IPC) devices comprise a wide range of systems, including multichamber or monochamber devices acting toward either the whole leg or only the calf, applying pressure either sequentially or uniformly. There is also a plantar compression system. The sleeves of those devices may be short, wrapping around just the lower leg, or long to wrap around the thigh as well. They are inflated one side at a time to compress the leg at intervals. Some types inflate sequentially, first around the lower leg and then the upper, to increase venous flow of the blood from the leg. The frequency of inflation can be fixed, or in more sophisticated systems, varies depending upon the rate of venous refill. The boots may be used in combination with graduated compression stockings.
Intermittent pneumatic compression is thought to reduce the risk of venous thrombosis by increasing the flow of venous blood through the deep veins of the leg to reduce the likelihood of thrombosis and stimulating release of intrinsic fibrinolytic substances [43].

Intermittent pneumatic compression devices, like graduate compression stockings, have mainly been used in surgical patients during and immediately after operations. A systematic review of the literature identified 22 randomised trials of IPC which included a total of 2779 patients. Use of IPC was associated with a $64 \%$ reduction in the odds of DVT $(p<0.00001)$ [37]. In 19 trials including 2255 patients assessing IPC as monotherapy, IPC produced a highly significant $66 \%$ reduction in DVT (112/1108 [10.1\%] IPC vs. 268/ 1147 [23.4\%] control, $p<0.00001)$. There was marginal evidence of heterogeneity of effect among these trials $(d f=28.4 ; p=0.03)$, but this was generated chiefly by one trial.

There is a lack of large RCTs evaluating whether a combination of mechanical methods might be more effective than a single mechanical method in prevention of DVT in post-stroke patients. The results of the ongoing large randomized trial CLOTS 3, which aims to compare the effectiveness of IPC vs. none in over 2800 stroke patients, will be available in May 2013 [44].

The first, small study evaluating the effectiveness of physical methods in preventing VTE was published in 1982. This study [45] included patients within 72 hours of having an acute stroke. The total number of included subjects was 26. Patients were randomized (method unclear) to receive an intermittent pneumatic compression device or not for 10 days. The diagnosis of DVT was provided by use of 125-I-fibrinogen. The test was performed within 24 hours of admission to hospital and scanning of the precordium and leg was carried out for 10 days. It was not clear whether the fibrinogen scans were assessed blind to the treatment allocation. The diagnosis of DVT proved by 125 -I-fibrinogen scan was confirmed in 12 patients out of 26 (46\%). Clinical signs of DVT were observed in only one patient with a positive scan although it is unclear which treatment this patient received. There were no significant differences in the radio-isotopic incidence of DVT between the treatment and control group ( 6 patients vs. 6 patients, $p=\mathrm{ns})$.

A more recent trial randomized 151 patients (from February 2002 to December 2003) with an intracerebral haemorrhage, within 48 hours since the onset, to elastic stockings (GCS) alone (77 patients) or combined 
GCS + IPC (74 patients). The primary outcome was assessed at day 10 and included a symptomatic and welldocumented VTE, or a death arising before day 10 due to pulmonary embolism, or an asymptomatic DVT of the lower limbs detected by compression ultrasonography (CUS). Outcome assessment was blinded. $133(88 \%)$ patients were evaluated at day 10 . No clinical suspicion of VTE arose before day 10. Fourteen patients died before CUS check but no death was definitely related to PE. Fourteen asymptomatic DVTs were detected by CUS: three $(4.7 \%)$ in the GCS + IPC group (all distal) and 11 (15.9\%) in the GCS group (three proximal and eight distal), relative risk (RR) 0.29 (95\% CI: 0.08 to 1.00 ). Absolute risk reduction was 0.11 (95\% CI: 0.00-0.22). The failure to follow up $12 \%$ of patients and imprecise estimate of effect, which was mainly based on distal DVTs (CUS has low sensitivity in reliable detection in that region), means that this trial cannot be regarded as adequate evidence on which to base treatment [46].

Another study [47] monitored the rate of DVT among non-haemorrhagic stroke patients admitted to their neurology service from October 1988 to June 1996. For part of this period some patients (249 in total) received just 5,000 $\mathrm{U}$ subcutaneous heparin twice daily and antiembolic hose. Another group of 432 nonambulatory stroke patients had sequential pneumatic compression devices applied to both legs in addition to subcutaneous heparin and antiembolic hose. DVT prophylaxis was started within 12 hours of admission. Twenty-three of 249 patients $(9.2 \%)$ treated with heparin alone developed DVT and six of those patients $(2.4 \%)$ developed PE. Only one DVT $(0.23 \%)$ and no PEs occurred among the 432 patients treated with sequential pneumatic compression devices + subcutaneous heparin + antiembolic hose. Clearly, this non-randomized trial is very prone to bias but it does suggest that the treatment is practical and acceptable to patients.

The large ongoing trial CLOTS 3 (2800 patients will be recruited to IPC or not) aims to determine whether it is effective in stroke patients [44].

Despite the poor evidence, IPC devices are recommended by both European and American guidelines in both ischaemic and haemorrhagic stroke patients $[17,18]$. Polish guidelines do not mention this method of VTE prophylaxis [21]. Most recent Polish recommendations accepted from ACCP guidelines accept the use of IPC in haemorrhagic stroke patients, and in ischaemic stroke patients as an addition to heparins [19].

\section{Summary of current recommendations}

- Heparins are the preferred method of VTE prophylaxis in both ischaemic and haemorrhagic stroke patients.

- LMWH are preferred over UFH.

- GCS are not recommended routinely in both ischaemic and haemorrhagic stroke patients.

- VTE prophylaxis in immobile patients with acute haemorrhagic stroke should be started 2-4 days after stroke onset.

- Adding IPC to heparins may provide additional benefit in preventing VTE in stroke patients.

Detailed Polish recommendations have been compiled in the newest version of those recommendations published in 2012 (see: Z6-53A to Z6-54C) [19].

\section{Conclusions}

In summary, there are several different methods which aim to reduce the risk of VTE. Not all of them seem to be effective. Heparins are recommended as a method of choice to prevent thromboembolic complications in stroke patients. However, there is no gold standard method for all post-stroke patients to prevent VTE. Inevitably, where reliable evidence is not available, variation in recommendations and clinical practice exists $[17-19,21,48,49]$.

\section{Disclosure}

Authors report no conflict of interest.

\section{References}

1. Geerts W.H., Bergqvist D., Pineo G.F., et al. American College of Chest Physicians. Prevention of venous thromboembolism: American College of Chest Physicians Evidence-Based Clinical Practice Guidelines (8th Edition). Chest 2008; 133: 381S-453S.

2. Dennis M., Sandercock P., Reid J., et al. CLOTS Trials Collaboration. Can clinical features distinguish between immobile patients with stroke at high and low risk of deep vein thrombosis? Statistical modelling based on the CLOTS trials cohorts. J Neurol Neurosurg Psychiatry 2011; 82: 1067-1073.

3. Kelly J., Rudd A., Lewis R.R., et al. Venous thromboembolism after acute ischemic stroke: a prospective study using magnetic resonance direct thrombus imaging. Stroke 2004; 35: 2320-2325.

4. Oczkowski W.J., Ginsberg J.S., Shin A., et al. Venous thromboembolism in patients undergoing rehabilitation for stroke. Arch Phys Med Rehabil 1992; 73: 712-716. 
5. The CLOTS Trials Collaboration. Effectiveness of thigh-length graduated compression stockings to reduce the risk of deep vein thrombosis after stroke (CLOTS trial 1): a multicentre, randomised controlled trial. Lancet 2009; 373: 1958-1965.

6. Bembenek J.P., Czlonkowska A., Karlinski M., et al. Early stroke-related DVT is more than just DVT diagnosed early after stroke onset. Thromb Res 2011; 128: 587-589.

7. Bembenek J.P., Karlinski M., Kobayashi A., et al. Deep venous thrombosis in acute stroke patients. Clin Appl Thromb Hemost 2012; 18: 258-264.

8. Gubitz G., Sandercock P., Counsell C. Anticoagulants for acute ischaemic stroke. Cochrane Database Syst Rev 2004; 3: CD000024.

9. McCarthy S.T., Turner J. Low-dose subcutaneous heparin in the prevention of deep vein thrombosis and pulmonary emboli following acute stroke. Age Ageing 1986; 15: 85-88.

10. Davenport R.J., Dennis M.S., Wellwood I., et al. Complications following acute stroke. Stroke 1996; 27: 415-420.

11. Gould M.K., Garcia D.A., Wren S.M., et al. American College of Chest Physicians. Prevention of VTE in nonorthopedic surgical patients: antithrombotic therapy and prevention of thrombosis, 9th ed: American College of Chest Physicians Evidence-Based Clinical Practice Guidelines. Chest 2012; 141: e227S-e277S.

12. Sandercock P.A., Counsell C., Tseng M.C. Low-molecularweight heparins or heparinoids versus standard unfractionated heparin for acute ischaemic stroke. Cochrane Database Syst Rev 2008; 3: CD000119.

13. International Stroke Trial Collaborative Group. The International Stroke Trial (IST) A randomised trial of aspirin, subcutaneous heparin, both or neither among 19435 patients with acute ischaemic stroke. Lancet 1997; 349: 1569-1581.

14. Sherman D., Alberts G., Bladin C., et al. The efficacy and safety of enoxaparin versus unfractioned heparin for the prevention of venous thromboembolism aftre acute ischaemic stroke (PREVAIL Study): an open-label randomised comparison. Lancet 2007; 369: 1347-1355.

15. Turpie A.G., Hull R.D., Schellong S.M., et al.; for the EXCLAIM Investigators. Venous thromboembolism risk in ischemic stroke patients receiving extended-duration enoxaparin prophylaxis: results from the EXCLAIM study. Stroke 2013; 44: 249-251.

16. Pineo G.F., Lin J., Annemans L. The economic impact of enoxaparin versus unfractionated heparin for prevention of venous thromboembolism in acute ischemic stroke patients. Clinicoecon Outcomes Res 2012; 4: 99-107.

17. The European Stroke Organisation (ESO) Executive Committee and the ESO Writing Committee. Guidelines for management of ischaemic stroke and transient ischaemic attack 2008. Cerebrovasc Dis 2008; 25: 457-507.

18. Lansberg M.G., O’Donnell M.J., Khatri P., et al.; American College of Chest Physicians. Antithrombotic and thrombolytic therapy for ischemic stroke: Antithrombotic therapy and prevention of thrombosis, 9th ed: American College of Chest Physicians Evidence-Based Clinical Practice Guidelines. Chest 2012; 141 (2 Suppl): e601S-e636S.

19. Zawilska K., Bała M., Błędowski P., et al. Polskie wytyczne profilaktyki i leczenia żylnej choroby zakrzepowo-zatorowej - aktualizacja 2012. Medycyna Prakt 2012; 10: 38-57.
20. Ginsberg J.S., Bates S.M., Oczkowski W., et al. Low-dose warfarin in rehabilitating stroke survivors. Thromb Res 2002; 107: 287-290.

21. Postępowanie w udarze mózgu. Wytyczne Grupy Ekspertów Grupy Ekspertów Sekcji Chorób Naczyniowych Polskiego Towarzystwa Neurologicznego. Neurol Neurochir Pol 2012; 46 (Suppl 1): S1-S122.

22. Harris W.H., Salzman E.W., Athanasoulis C.A., et al. Aspirin prophylaxis of venous thromboembolism after total hip replacement. N Engl J Med 1977; 297: 1246-1249.

23. Falck-Ytter Y., Francis C.W., Johanson N.A., et al. Prevention of VTE in orthopedic surgery patients: Antithrombotic therapy and prevention of thrombosis, 9th ed. American College of Chest Physicians evidence-based clinical practice guidelines. Chest 2012; 141: e278S-e325S.

24. Lotke P.A., Lonner J.H. Deep venous thrombosis prophylaxis: better living through chemistry - in opposition. $J$ Arthroplasty 2005; 20 (4 Suppl 2): 15-17.

25. Pulmonary Embolus Prevention Trial (PEP) Collaborative Group. Prevention of pulmonary embolism and deep vein thrombosis with low dose aspirin. Lancet 1999; 355: 1303.

26. Chinese Acute Stroke Trial (CAST) Collaborative Group. CAST: a randomised placebo controlled trial of early aspirin use in 21106 patients with acute ischaemic stroke. Lancet 1997; 349: 1641-1649.

27. Chen Z.M., Sandercock P., Pan H.C., et al. Indications for early aspirin use in acute ischemic stroke : A combined analysis of 40000 randomized patients from the Chinese acute stroke trial and the international stroke trial. On behalf of the CAST and IST collaborative groups. Stroke 2000; 31: 1240-1249.

28. Karthikeyan G., Eikelboom J.W., Turpie A.G., et al. Does acetyl salicylic acid (ASA) have a role in the prevention of venous thromboembolism? Br J Haematol 2009; 146: 142-149.

29. Sandercock P.A., Counsell C., Gubitz G.J., et al. Antiplatelet therapy for acute ischaemic stroke. Cochrane Database Syst Rev 2008; 3: CD000029.

30. Zawilska K., Jaeschke J., Tomkowski W., et al. Polskie wytyczne profilaktyki i leczenia żylnej choroby zakrzepowo-zatorowej. Medycyna Prakt 2009; 4: 1-78.

31. Asplund K. Haemodilution for acute ischaemic stroke. Cochrane Database Syst Rev 2002; 4: CD000103.

32. Kelly J., Hunt B.J., Lewis R.R., et al. Dehydration and venous thromboembolism after acute stroke. QJM 2004; 97: 293-296.

33. Sundseth A., Thommessen B., Rønning O.M. Outcome after mobilization within 24 hours of acute stroke: a randomized controlled trial. Stroke 2012; 43: 2389-2394.

34. Sorbello D., Dewey H.M., Churilov L., et al. Very early mobilisation and complications in the first 3 months after stroke: further results from phase II of A Very Early Rehabilitation Trial (AVERT). Cerebrovasc Dis 2009; 28: 378-383.

35. Wells P.S., Lensing A.W.A., Hirsh J. Graduated compression stockings in the prevention of postoperative venous thromboembolism: a meta analysis. Arch Intern Med 1994; 154: 67-72.

36. Agu O., Hamilton G., Baker D. Graduated compression stockings in the prevention of venous thromboembolism. BrJ Surg 1999; 86: 992-1004. 
37. Roderick P., Ferris G., Wilson K., et al. Towards evidence-based guidelines for the prevention of venous thromboembolism: systematic reviews of mechanical methods, oral anticoagulation, dextran and regional anaesthesia as thromboprophylaxis. Health Technol Assess 2005; 9: 1-78.

38. Kierkegaard A., Norgren L. Graduated compression stockings in the prevention of deep vein thrombosis in patients with acute myocardial infarction. Eur Heart J 1993; 14: 1365-1368.

39. Muir K.W., Watt A., Baxter G., et al. Randomised trial of graded compression stockings for prevention of deep-vein thrombosis after acute stroke. QJM 2000; 93: 359-364.

40. CLOTS (Clots in Legs Or sTockings after Stroke) Trial Collaboration. Thigh-length versus below-knee stockings for deep venous thrombosis prophylaxis after stroke: a randomized trial. Ann Intern Med 2010; 153: 553-562.

41. Kay T.W., Martin F.I. Heel ulcers in patients with long standing diabetes who wear antiembolism stockings. Med J Aust 1986; 145: 290-291.

42. Merrett N.D., Hanel K.C. Ischaemic complications of graduated compression stockings in the treatment of deep vein thrombosis. Postgraduate Med J 1993; 69: 232-234.

43. The CLOTS Trials Collaboration. Effectiveness of thigh-length graduated compression stockings to reduce the risk of deep vein thrombosis after stroke (CLOTS trial 1): a multicentre, randomised controlled trial. Lancet 2009; 373: 1958-1965.

44. Dennis M., Sandercock P., Reid J., et al. CLOTS Trials Collaboration. Does intermittent pneumatic compression reduce the risk of post stroke deep vein thrombosis? The CLOTS 3 trial: study protocol for a randomized controlled trial. Trials 2012; 13: 26 .

45. Prasad B.K., Banerjee A.K., Howard H. Incidence of deep vein thrombosis and the effect of pneumatic compression of the calf in elderly hemiplegics. Age Ageing 1982; 11: 42-44.

46. Lacut K., Bressollette L., Le Gal G., et al. Prevention of venous thrombosis in patients with acute intracerebral hemorrhage. Neurology 2005; 65: 865-869.

47. Kamran S., Downey D., Ruff R. Pneumatic sequential compression reduces the risk of deep vein thrombosis in stroke patients. Neurology 1998; 50: 1683-1688.

48. National Institute for Health and Clinical Excellence. Venous thromboembolism: reducing the risk-full guideline. July, 2012; http://guidance.nice.org.uk/CG92.

49. SIGN Guideline 118. Management of patients with stroke: rehabilitation, prevention and management of complications, and discharge planning; http://www.sign.ac.uk/pdf/sign118.pdf. 